\title{
A Study of Wire Breakup and In-Flight Particle Behavior During Wire Flame Spraying of Aluminum
}

\author{
G. D. Lunn ${ }^{1,2}$ - M. A. Riley ${ }^{1}$ D. G. McCartney ${ }^{2}$
}

Submitted: 25 May 2017/in revised form: 18 August 2017/Published online: 25 September 2017

(c) The Author(s) 2017. This article is an open access publication

\begin{abstract}
Although wire flame spraying has been used for many years, there has been relatively little attention given to understanding the process dynamics. In this work, imaging of the molten wire tip, particle imaging using the Oseir SprayWatch system and particle capture (wipe tests) have all been employed to quantify plume behavior. Aluminum wire feedstock is melted and then breaks up close to the exit of the spray nozzle in a non-axisymmetric manor. The mean velocity and diameter of the particles detected by the SprayWatch system change little with standoff distance with values of approximately $280 \mathrm{~m} / \mathrm{s}$ and $70 \mu \mathrm{m}$, respectively, for the spray parameters employed. The particle diagnostic system could not detect particles $\lesssim 45 \mu \mathrm{m}$ in diameter, and it is estimated that these account for no more than $53 \%$ of the sprayed material. Overall, wire flame spraying generates a surprisingly stable particle stream.
\end{abstract}

Keywords thermal spray diagnostics - thermally sprayed aluminum $\cdot$ wire breakup $\cdot$ wire flame spraying

\section{List of symbols \\ $v \quad$ Velocity \\ $l \quad$ Length \\ $\rho \quad$ Density \\ We Weber number \\ $\gamma \quad$ Surface tension}

\footnotetext{
G. D. Lunn

geoff.lunn@live.com

1 TWI Ltd, Granta Park, Cambridge CB21 6AL, UK

2 Advanced Materials Group, Faculty of Engineering, University of Nottingham, University Park, Nottingham NG7 2RD, UK
}

\author{
Abbreviations \\ HVOF High-velocity oxy-fuel \\ PFS Powder flame spraying \\ PS Plasma spraying \\ TWAS Twin wire arc spraying \\ WFS Wire flame spraying
}

\section{Introduction}

Thermal spray diagnostic systems typically attempt to measure the velocity, size and temperature of the particles within a thermal spray plume. Research using these systems has particularly focused on analyzing thermal spray processes such as plasma spraying (PS) and high-velocity oxy-fuel (HVOF) thermal spraying. The information provided has helped researchers understand the particle dynamics within the plume of these systems, as well as improve process repeatability and reliability (Ref 1 ). Generally, diagnostic systems detect particles by optical methods based on either their emitted light or by utilizing external lighting (typically a laser) to illuminate the particles if they are of low temperature. They typically use a time-of-flight method to calculate velocity, intensity of the signal to ascertain particle size and two-wavelength pyrometery (TWP) on the emitted light from the particles to determine their temperature $(\operatorname{Ref} 1,2)$. Therefore, when external lighting is used, temperature measurements are not feasible.

There are a variety of different systems available to measure in-flight particle properties with their own individual subtleties as reported in Ref 1 . The present study utilizes an approach conceptually similar to particle image velocimetry. However, instead of determining velocity fields within a gas by introducing and imaging small tracer 
particles as is done in particle image velocimetry, it is the particles already within the stream (i.e., thermal spray particles) which are monitored using a time-of-flight method. Particles are imaged several times and the displacements of their images on a CCD camera are used to calculate velocity. Systems based on particle velocimetry give individual particle information over a relatively large measurement region. An example of a commercially available system is SprayWatch (Oseir, Tampere, Finland), and this system is based around a specialist CCD camera and primarily utilizes the particle velocimetry method (Ref $2,3)$. This system can be used with cold thermal spray particles by illuminating the particles with a laser. Specifically, it combines a high-power pulsed diode laser with a fast shutter CCD camera. This permits a multi-exposed image to be taken showing the particles at multiple times. The system also allows for the determination of the size of the detected particles by measuring their diameter (normal to their direction of travel) in the images captured (Ref 3).

In order to understand how particles interact with the substrate, wipe tests are often also used to assess the flattening behavior of the particles as they strike the substrate. A wipe test is where a substrate is exposed to the thermal spray plume for a very short time period (fractions of a second), and thus, isolated splats are deposited and an assessment of the instantaneous particle characteristics can be made.

Despite the availability of sophisticated particle diagnostic systems, relatively little attention has been paid to using them to investigate spray processes involving wire feedstock. The process of spraying with a wire or wires is a complex one as it involves wire breakup and subsequent heat and momentum transfer to particles which may further disintegrate during flight. Wire breakup phenomena have to some extent been studied in relation to twin wire arc spraying (TWAS) (Ref 4-7), and it has been shown that the electric arc struck between the feedstock wires attaches differently to the anode and cathode. The arc attachment is localized on the cathode and leads to different heating and melting behavior of the wires. It is reported that a thin pool of molten metal forms on the outer layer of the wire (Ref 4). Due to the action of the atomizing gas, this layer is pushed to form a 'jet' at the tip of the wire. The jet is broken up through one of several mechanisms depending on the dynamics of the flow, and researchers observe axisymmetric Rayleigh breakup, non-axisymmetric Rayleigh breakup and membrane type breakup (Ref 5).

WFS has apparently received little attention with regard to the measurement of in-flight particle parameters. This could well be due to the low added value applications for which it is typically employed, e.g., cathodic protective coatings on pipes (Ref 8 ). However, in recent years there has been a growing interest in depositing WFS coatings for more high-technology applications, for example (Ref $9,10)$. Due to this lack of in-flight particle investigation, there is little information available regarding the characteristics and behavior of the wire flame spray plume which limits our ability to better understand the relationship between the process parameters and the properties of coatings deposited by WFS. In the reference literature, powder flame spraying and wire flame spraying are typically grouped together and spray particle velocities quoted for them are $50-100 \mathrm{~m} / \mathrm{s}(\operatorname{Ref} 11)$ or 100-200 m/s (Ref 12), but it is difficult to find evidential basis for these figures. In one study, Dykhuizen and Neiser measured particle velocities in a WFS system at a single location $70 \mathrm{~mm}$ from the gun in order to develop a closed-loop control system (Ref 13). In this arrangement, they measured particle velocities of $50-400 \mathrm{~m} / \mathrm{s}$ (Ref 13); somewhat higher than typically quoted. Neiser et al. also measured particle velocities of the related wire-fed HVOF process. In their work particle, velocities of 140-270 m/s (Ref 14) were recorded at a location $40 \mathrm{~mm}$ downstream from the gun. Work carried out investigating powder flame spraying found particle velocities $<50 \mathrm{~m} / \mathrm{s}$ (Ref 15); these are more akin to the often quoted figures.

In relation to the use of WFS for use in more advanced applications, a better understanding of wire break up and particle behavior is needed to achieve more consistent coating microstructures and functional performance. Therefore, the overall aim of the work presented in this paper was to elucidate important features of the WFS process for aluminum using several techniques. Optical imaging was used to examine wire breakup, an in-flight particle sensor was employed to measure the particle size and velocity along with the consistency of the plume, and wipe tests were conducted to provide a separate assessment of the particle distribution in the plume.

\section{Experimental Setup}

\section{Materials}

Industrially, pure $2.3 \mathrm{~mm}$ diameter aluminum wire was used as feedstock wire for the flame spraying experiments. Substrates of dimensions $40 \times 40 \mathrm{~mm}$ were used for the wipe test trials, and these were machined from BS 4360:1990-50D steel. These were polished to a $0.25 \mu \mathrm{m}$ surface finish prior to spraying.

\section{Spray Processing}

Flame spraying was performed with a MK73 (Metallisation Ltd., Dudley, UK) wire flame spray gun. The gun was 
mounted on a 6-axis industrial robot for positional repeatability. A near-stoichiometric oxy-fuel gas mixture was used throughout all the experiments. The flow parameters (as indicated by the MK73 instrument panel) that were employed are shown in Table 1. The baseline settings were used throughout most the experiments, and the $\pm 20 \%$ settings were used (where indicated) to judge the effect of atomizing air flow rate changes.

\section{Spray Diagnostics}

The experimental arrangement of the particle diagnostic system (SprayWatch 2i, Oseir, Finland) is shown schematically in Fig. 1. In this configuration, the camera captures shadow-graph images of the plume illuminated by

Table 1 Flow parameters used for wire flame spray experiments

\begin{tabular}{llcc}
\hline Parameter & \multicolumn{3}{c}{ Condition } \\
\cline { 2 - 4 } & $-20 \%$ & Baseline & $+20 \%$ \\
\hline Air flow rate, $l_{n} \mathrm{~s}^{-1}$ & 6.1 & 7.7 & 9.2 \\
Propane flow rate $(\mathrm{a})$ & 3.75 & 3.75 & 3.75 \\
Oxygen flow rate(a) & 3.75 & 3.75 & 3.75 \\
Wire feed rate, $\mathrm{m} / \mathrm{s}$ & 0.04 & 0.04 & 0.04 \\
\hline
\end{tabular}

(a) Flow meter reading (FMR), arbitrary units as indicated on MK 73 instruments

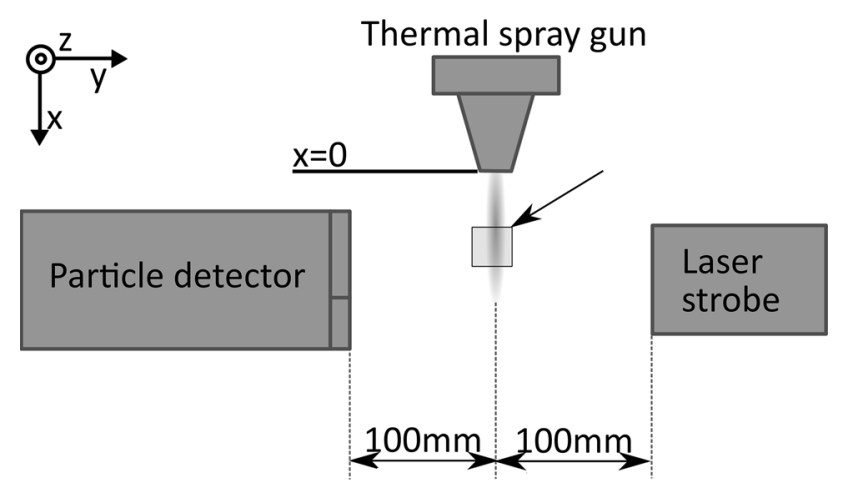

Fig. 1 Schematic diagram of the setup for measuring in-flight particle parameters using a backlit arrangement. The origin $(x=y=z=0)$ is at the center of the nozzle exit, and the $x$ direction is along the plume axis. The arrow indicates the typical measurement region the laser in a backlit configuration. Within a single frame, the laser strobe illuminates the image three times at predetermined intervals. This triple exposed image means that each particle is shown three times in a single CCD camera image. Image analysis is used to detect triplet particle images. Using the known lens magnification, the particle size is determined directly from the particle images and the velocity by the particle spacing in the image and the time interval for illumination as detailed in Ref 3.

The system was set up such that the plume was located centrally between the particle detector and the laser strobe light source and $100 \mathrm{~mm}$ from each. The particle detector was fitted with a close-up lens to create a measurement volume of $10.9 \times 10.2 \times 11.6 \mathrm{~mm}$ in $x, z$ and $y$, respectively. The location of this measurement volume was moved in the plume in the $x$ and $z$ direction by moving the flame spray gun in relation to the particle detector in line with Fig. 2. Thus, 151 individual regions spaced $10 \mathrm{~mm}$ apart were measured with a small 1.2-mm overlap. Data were analyzed at specific locations; in addition, the detected particle data from each run were merged together to give an overall description of how the whole plume behaved. Aluminum particle temperatures are low in WFS and could not be measured with this system.

\section{Wire Breakup Imaging}

Images of the wire breakup were captured using the particle diagnostic system and the laser strobe. In this arrangement, the laser was set to illuminate only once during the camera exposure time, leading to single exposed images. The fast laser strobe allowed clear images of the highly dynamic process to be captured, but the frame rate of the camera was too slow to allow the development of a wire breakup event. Thus, many images were taken of multiple wire breakup events and from these images of representative examples are shown.

\section{Wipe Tests}

Wipe tests were performed using an experimental arrangement (Fig. 3) constructed to collect the splats from the thermal spray plume. This involved a shutter with a
Fig. 2 Schematic diagram of the locations within the $x-y$ plane $(z=0)$ for particle parameter measurements within the spray plume

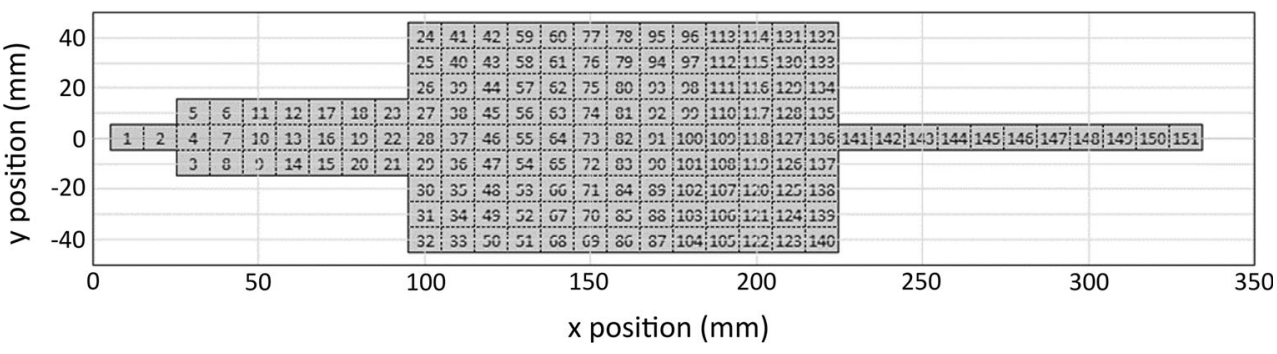


$2 \mathrm{~mm}$ wide slit which was passed across the sample such that a particular point was exposed to the plume for $\sim 0.3 \times 10^{-3} \mathrm{~s}$, as calibrated with a photodiode and oscilloscope. Samples were placed at representative spraying distances for comparison with particle diagnostics data, and associated splats were collected. Macro-photographic images were taken of the wipe tests, Fiji image analysis software (Ref 16) was used to segment and record

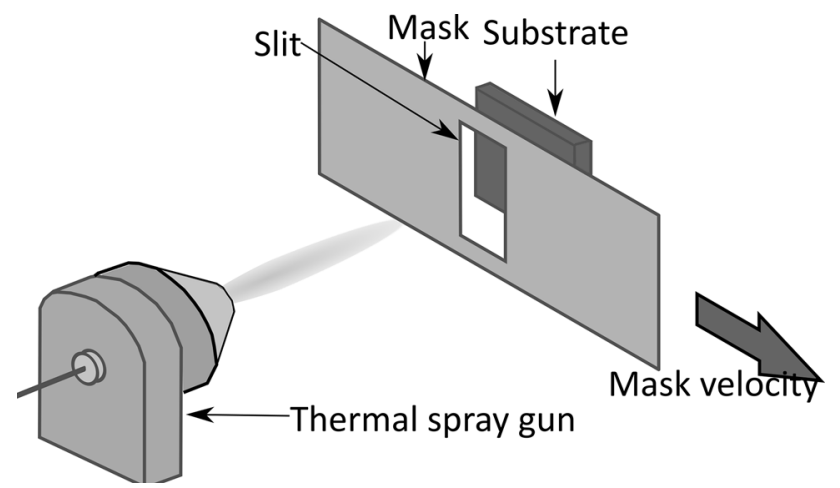

Fig. 3 Schematic diagram of the arrangement for the wipe test employing a $2 \mathrm{~mm}$ wide slit in a mask which is traversed across the substrate to expose it briefly to the particle spray the location of each splat, and from this splat distributions were determined. In addition, the volume of a random sample of splats was measured through focus variation microscopy using an Alicona IF SL (Alicona imaging $\mathrm{GmbH}$, Austria).

\section{Results}

\section{Primary Wire Breakup}

Figure 4 shows six non-consecutive images of the wire tip taken over a $40 \mathrm{~s}$ time period. The end of the flame spray gun is indicated by the dashed line on the left side of each image. From the images, it is clear that the wire formed a conical shape with a mean angle of $\sim 9.5^{\circ}$ and this angle was relatively constant (with a standard deviation of $1.4^{\circ}$ ). The wire emerged from the end of the gun with a relatively constant diameter, mean of $1.02 \mathrm{~mm}$ (standard deviation of $0.05 \mathrm{~mm}$ ), significantly thinner than the diameter of the initial feedstock, $2.3 \mathrm{~mm}$. Thus, the cone must have started to thin, by surface melting, within the gun, and out of sight of the camera.

The series of images in Fig. 4 show the process of wire breakup. Figure 4(a) clearly shows waves of molten
Fig. 4 Set of six non-sequential wire tip images taken with SprayWatch and a laser strobe backlight. The vertical dashed lines indicated the position of the end of the thermal spray gun

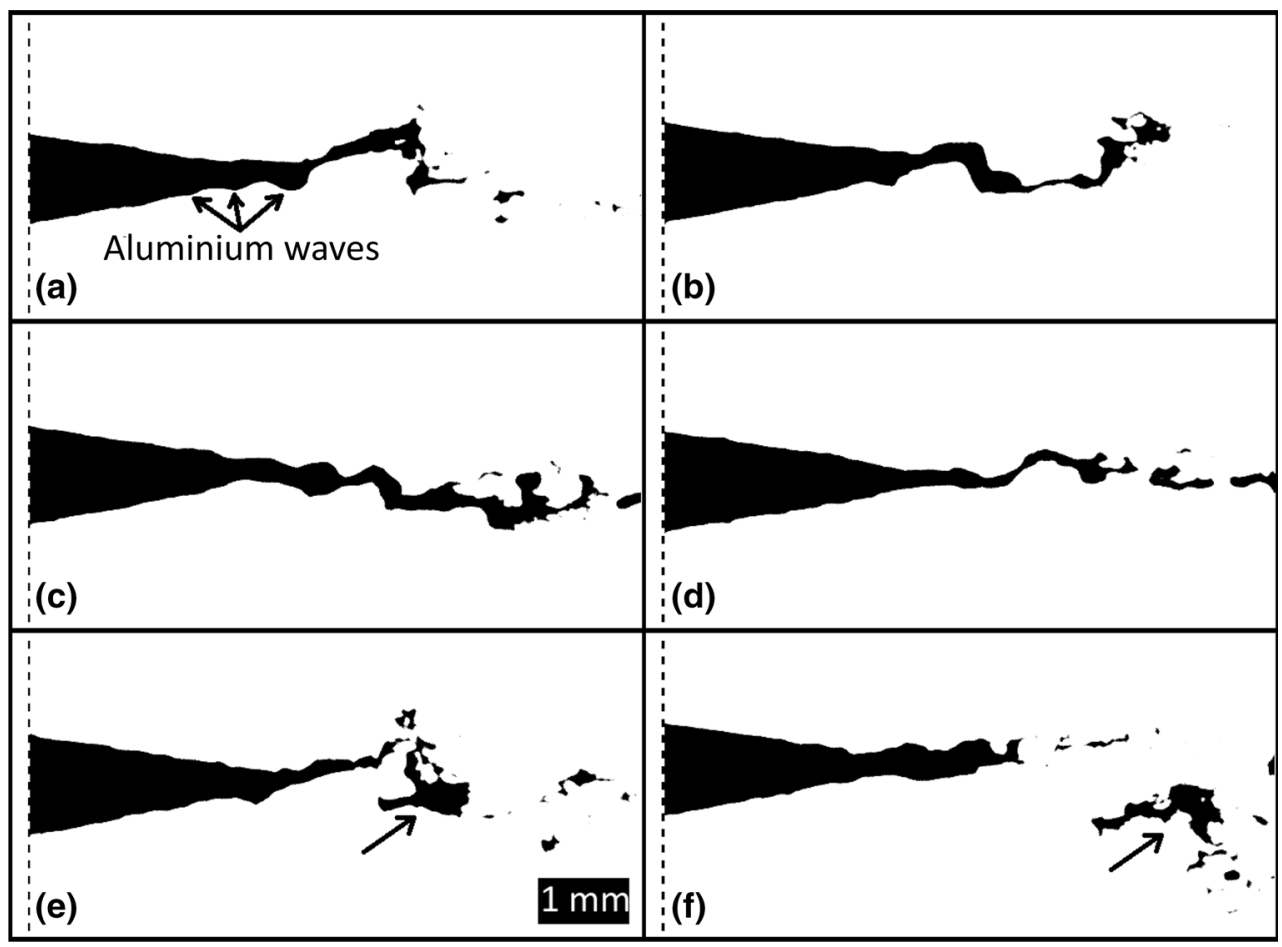


aluminum were pushed toward the end of the wire tip. Figure 4(a)-(d) shows that these waves of material increased the size of the molten pool of material suspended from the end of the wire tip. The images show that the molten metal pool formed a thin liquid jet which was subjected to the aerodynamic forces within the plume, often forming waves as shown in Fig. 4(b)-(d). These waves evidently thinned and broke up into irregular shaped droplets as shown in Fig. 4(d), or larger sections of the ligament broke off at once creating larger irregular shaped molten particles as highlighted by the arrows in images Fig. 4(e) and (f).

The effect of atomizing air flow rate on the wire breakup was investigated by varying it by $\pm 20 \%$ from its baseline value. Images of the wire were almost identical to those at the baseline values, and the diameter of the wire at the end of the gun did not significantly change by varying the atomizing air flow rate $(1.07$ and $1.17 \mathrm{~mm}$ for $-20 \%$ and $+20 \%$ changes in air flow rate, respectively), nor did the angle of the cone $\left(8.8^{\circ}\right.$ and $9.5^{\circ}$ for the $-20 \%$ and $+20 \%$ changes in air flow rate, respectively). There is some evidence that there was slightly less variability on the tip length at the higher atomizing air flow rates, indicated by the slightly narrower distribution of measured wire tip lengths shown in Fig. 5, but the magnitude of this effect is small at best.

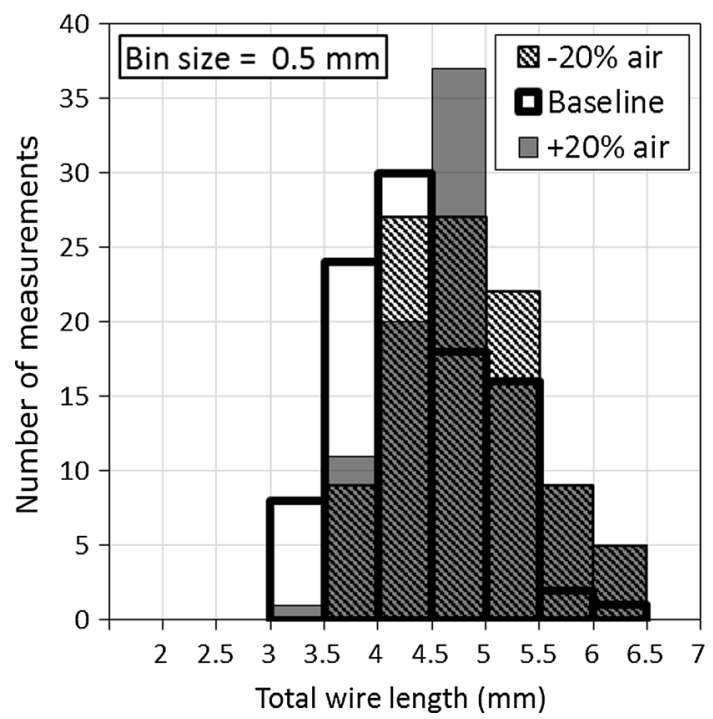

Fig. 5 Histogram showing the distribution of wire tip length (measured from the gun exit). Data are shown for the baseline air flow rate and for deviations of $\pm 20 \%$ from the baseline value

\section{In-Flight Particle Measurements}

\section{Representative Standoff Distance}

The mean measured velocity of the spray particles at a spraying distance of $\sim 150 \mathrm{~mm}$ was $287 \mathrm{~m} / \mathrm{s}$, the median velocity was $281 \mathrm{~m} / \mathrm{s}$, and the standard deviation of the sample data was $62 \mathrm{~m} / \mathrm{s}$ as shown by the histogram in Fig. 6(a). A normal distribution curve has been fitted to this plot and appears to fit well. It should be noted that the fitted normal distribution in Fig. 6(a) has a standard deviation of $50 \mathrm{~m} / \mathrm{s}$. This figure is lower than that calculated from the experimental data because the small number of very high
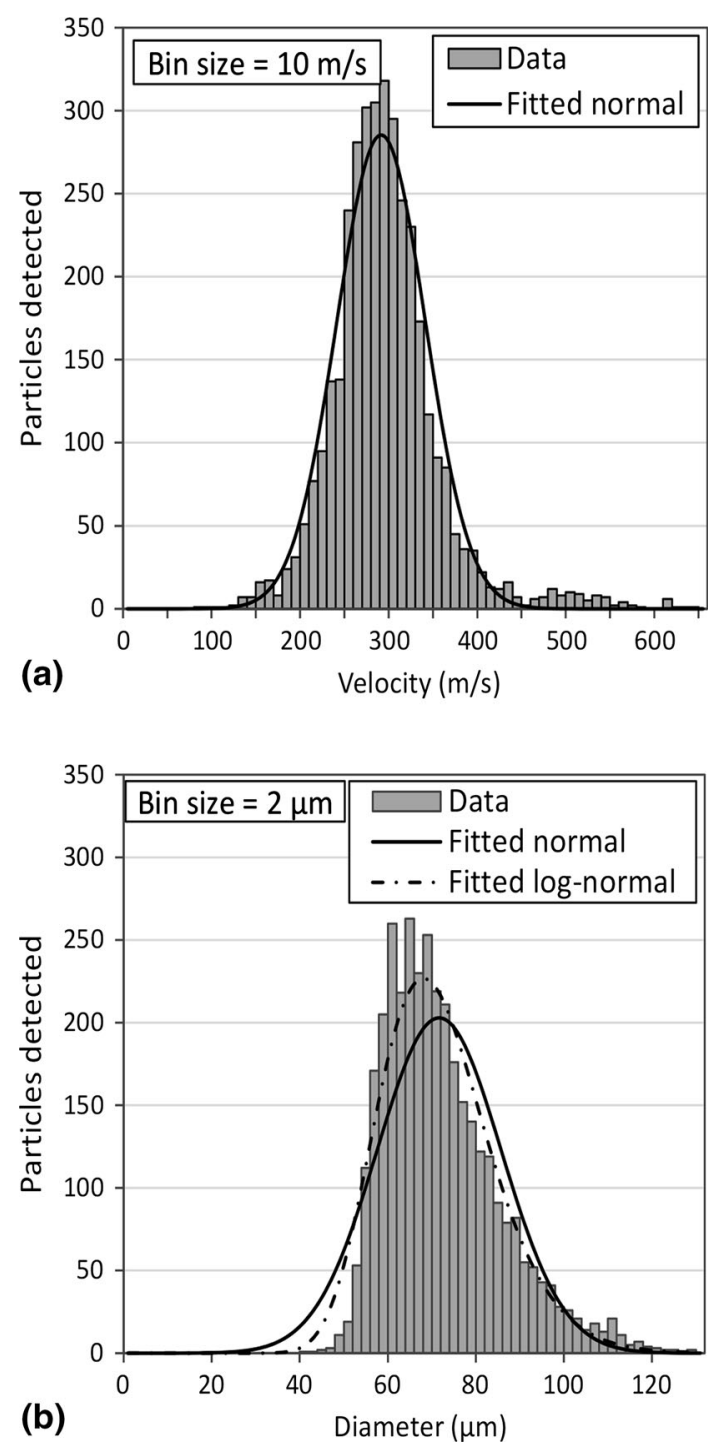

Fig. 6 Histograms showing the distribution of (a) particle velocity measurements and (b) particle diameter measurements. Solid lines show fitted distributions. In (a) a normal distribution and in (b) a lognormal distribution 
velocity data points, which are probably noise in the data, has been ignored in the fitting procedure.

The mean measured particle diameter measured was $71 \mu \mathrm{m}$, the median diameter was $68 \mu \mathrm{m}$, and the data had a standard deviation of $14 \mu \mathrm{m}$ (Fig. 6b). A log-normal distribution appears to fit the data better than a normal distribution as shown in Fig. 6(b) but neither fit particularly well at the low diameter end of the distribution.

\section{Consistency of Plume Measurement}

The time series measurements of the individual particle velocities and diameters at a standoff distance of $\sim 150 \mathrm{~mm}$ (Fig. 7) show that over the course of a measurement run (approximately $40 \mathrm{~s}$ ) there was no statistically significant trend with time and so the plume was
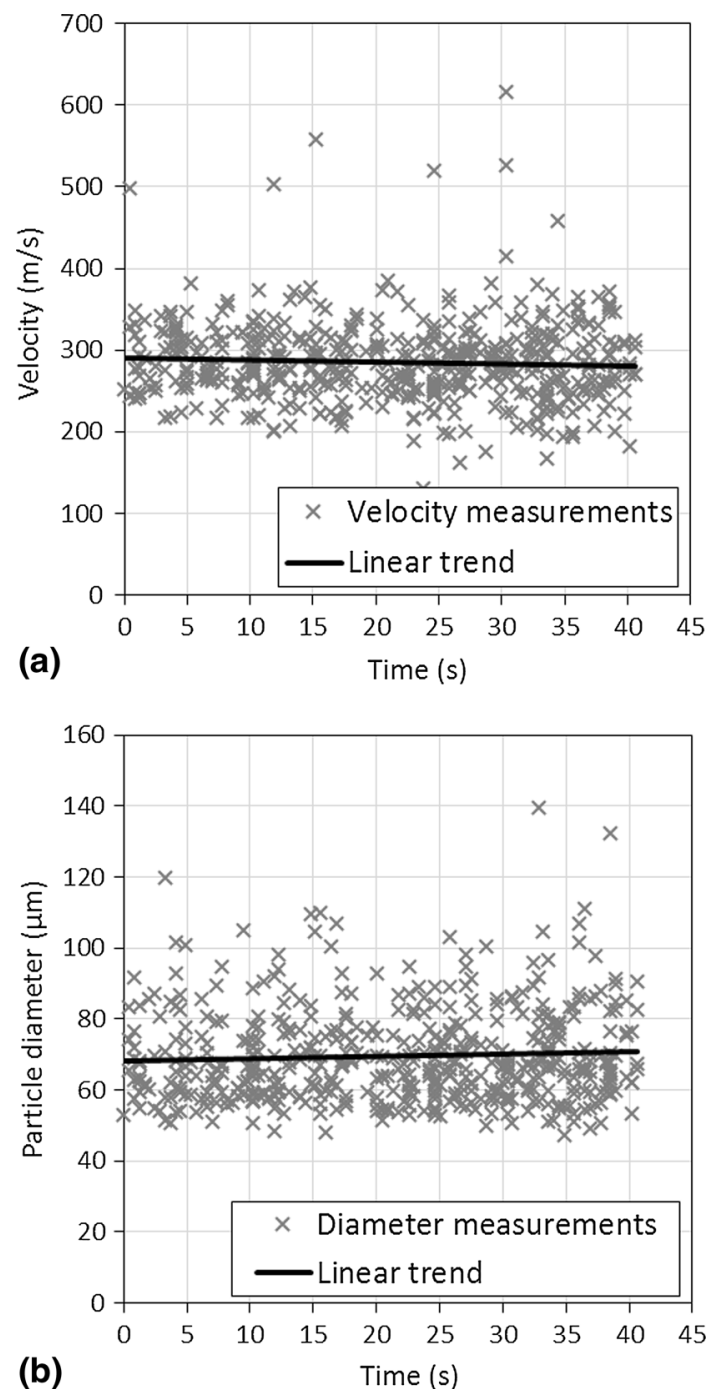

Fig. 7 SprayWatch measurements showing the variation of (a) particle velocity and (b) particle diameter with spraying time. Measurements taken on the plume centerline at a distance of $\sim 150 \mathrm{~mm}$ from the exit of the gun stable over the course of a measurement run. Repeat runs were performed at the start and end of each spray session (Table 2). The results show that average velocity and particle size within the plume were consistent over the course of spray runs (approximately an hour of continuous spraying). Table 2 also shows the average properties were consistent from spray run to spray run (spaced over the course of several months).

\section{Varying Atomizing Flow Rate}

Higher atomizing gas flow rates lead to marginally higher particle velocities as shown in Fig. 8(a). However, the difference was well within one standard deviation (Table 3). The velocity distribution is based on a large number of data points so these small changes may be statistically significant. The measured particle size distributions are broadly similar at the higher and lower atomizing gas flows (Fig. 8b) with a noticeable lower size cutoff at around $50 \mu \mathrm{m}$.

\section{Spatial Distribution}

Figure 9 represents the detected particles from plume measurements discretized into bins of size $5 \mathrm{~mm}$ in the $\mathrm{x}$ direction at increasing axial distance from the nozzle. The boundaries represent 50,75 and $90 \%$ of the particles detected within that bin and are displayed in a contour format. The figure demonstrates that the width of the thermal spray plume is shown to increase with standoff distance. However, even at $200 \mathrm{~mm}$ it remained relatively narrow with $50 \%$ of the detected particles within $\pm 7.5 \mathrm{~mm}$ of the centerline. Figure 10 shows the average particle velocity for particles detected at different locations in the thermal spray plume, and in this plot the measurement domain has been discretized into $1 \mathrm{~mm}$ square bins in $x$ and $z$ as defined in Fig. 1. The figure shows that the velocities of the particles are greatest in the central cone of the plume and decrease radially away from the center of it, where the velocities fell to around $200 \mathrm{~m} / \mathrm{s}$. At these locations (greater than $\pm 20 \mathrm{~mm}$ from the centerline throughout most

Table 2 Summary of particle velocities and diameters at $\sim 150 \mathrm{~mm}$ standoff distance for measurements at the beginning and end of three separate spray measurement runs

\begin{tabular}{lrrrrrrrrr}
\hline & \multicolumn{2}{c}{ Spray run 1 } & & \multicolumn{2}{c}{ Spray run 2 } & & \multicolumn{2}{c}{ Spray run 3 } \\
\cline { 2 - 3 } & Start & End & & Start & End & & Start & End \\
\hline Mean velocity, m/s & 272 & 286 & & 285 & 291 & & 298 & 294 \\
Standard deviation, $\mathrm{m} / \mathrm{s}$ & 45 & 67 & & 51 & 68 & & 70 & 63 \\
Mean diameter, $\mu \mathrm{m}$ & 70 & 71 & & 70 & 70 & & 71 & 72 \\
Standard deviation, $\mu \mathrm{m}$ & 14 & 15 & & 13 & 13 & & 14 & 15 \\
\hline
\end{tabular}



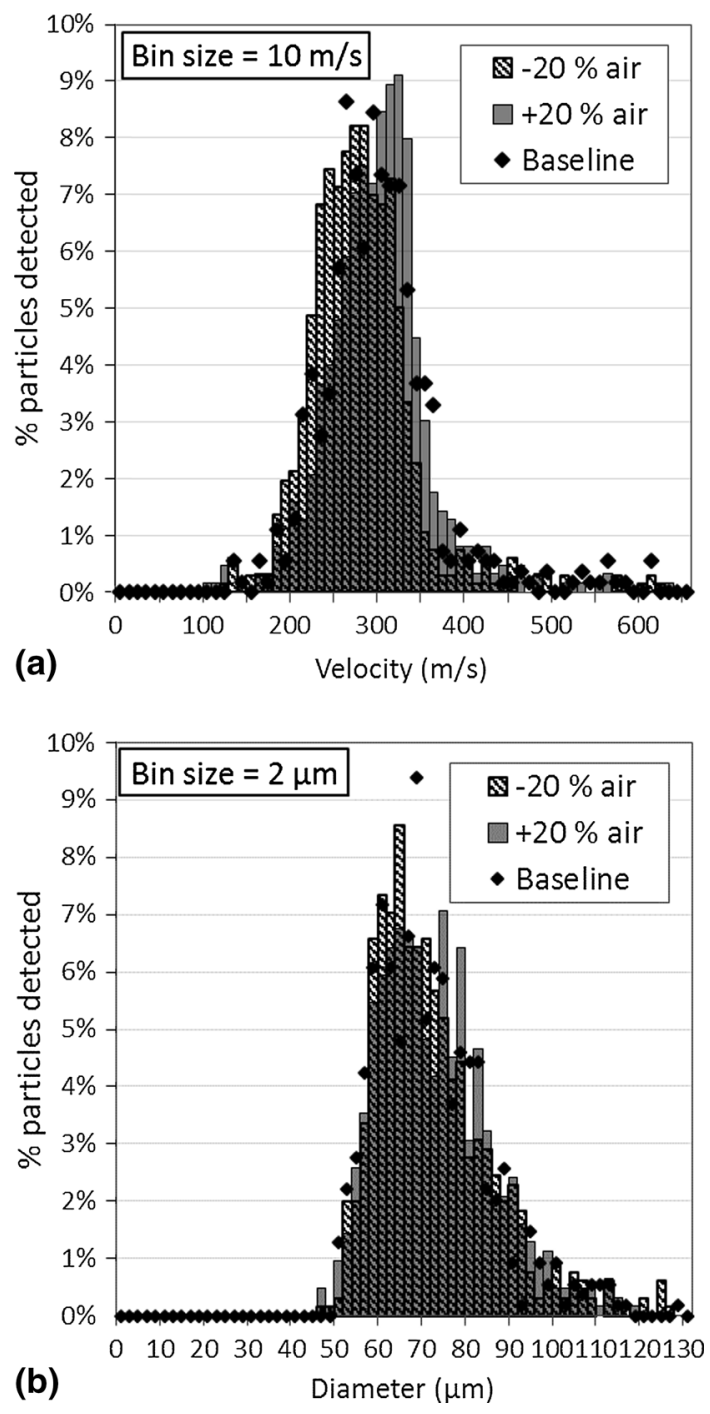

Fig. 8 Histograms showing the distributions of (a) particle velocity and (b) particle diameter. Measurements taken on the plume centerline at a distance of $\sim 150 \mathrm{~mm}$ from the exit of the gun. Data are shown for the baseline air flow rate and for deviations of $\pm 20 \%$ from the baseline value

Table 3 Effect of atomizing gas flow rate on particle velocity

\begin{tabular}{lrcr}
\hline & \multicolumn{3}{c}{ Atomizing gas flow rate } \\
\cline { 2 - 4 } & $-20 \%$ & Baseline & $+20 \%$ \\
\hline Mean velocity, $\mathrm{m} / \mathrm{s}$ & 272 & 287 & 294 \\
Standard deviation, $\mathrm{m} / \mathrm{s}$ & 63 & 62 & 63 \\
\hline
\end{tabular}

the plume), the numbers of detected particles were small enough that they can be considered little more than noise. The particle velocity within the central cone increased until $\sim 70 \mathrm{~mm}$ from the nozzle exit, and it then remained relatively constant up to $\sim 150 \mathrm{~mm}$ and then started to gradually decline. Nevertheless, the detected velocities were typically still $>250 \mathrm{~m} / \mathrm{s}$ until the end of standoff distances measured (Fig. 11). The detected particle diameters were shown to be practically constant along the centerline throughout the entire measurement region (Fig. 12).

\section{Wipe Test Results}

Figure 13 shows the spatial distribution of splats along the $z$-axis (as defined in Fig. 1) for 5 wipe tests on polished steel. The location of these splats is shown to be approximately normally distributed along this axis for the 5 wipe test samples. Particle distribution data from the SprayWatch system for the same region are also plotted. There is some scatter in the data, but the wipe tests (which represent $0.3 \times 10^{-3} \mathrm{~s}$ of spray time) seem to have a distribution which is consistent with the equivalent data obtained from the SprayWatch measurements which is also plotted on the graph.

\section{Discussion}

\section{Wire Breakup Considerations}

Wire was successfully imaged as it atomized. There were no significant differences observed in the wire breakup when modifying the atomizing air flow $( \pm 20 \%$ from the baseline value). Waves of metal are clearly observed on the molten surface of the wire. In the wire flame spray process, a shearing force is applied by the fast moving atomizing air flowing over the molten surface. This is probably responsible for transporting molten metal to the tip of the wire where, because of viscous forces, it forms a molten tip or jet. This appears to be in line with previous discussions of liquid jet disintegration both generally (Ref 17) and in the context of twin wire arc spray (Ref 4-7). The propensity for the jet to breakup is expressed by the Weber number (Eq 1).

$\mathrm{We}=\frac{v^{2} l \rho}{\gamma}$

where $v$ is the atomizing air velocity, $l$ is the length of the molten zone at the tip, $\rho$ is the atomizing air density and $\gamma$ is the surface tension of liquid metal. The value of the Weber number determines the breakup regime. The images taken in this investigation appear to indicate a mainly nonaxisymmetric form of breakup, and this implies a Weber number of 15-25 for all air flow rates employed (Ref 5) and suggests that primary atomization is similar in both wire flame and twin wire arc spraying. However, the estimate for the Weber number calculated from the air volume flow rate and $\gamma$ from Ref 18 gives a Weber number of 300-600 and this range of values would suggest membrane type breakup would be dominant. This discrepancy is probably 

the distribution of particles at different standoff distances within the plume. Colored area represents where 90,75 and $50 \%$ of the particles are detected

Fig. 10 Plot showing the mean particle speed at each measured location within the spray plume
Fig. 9 Contour plot detailing
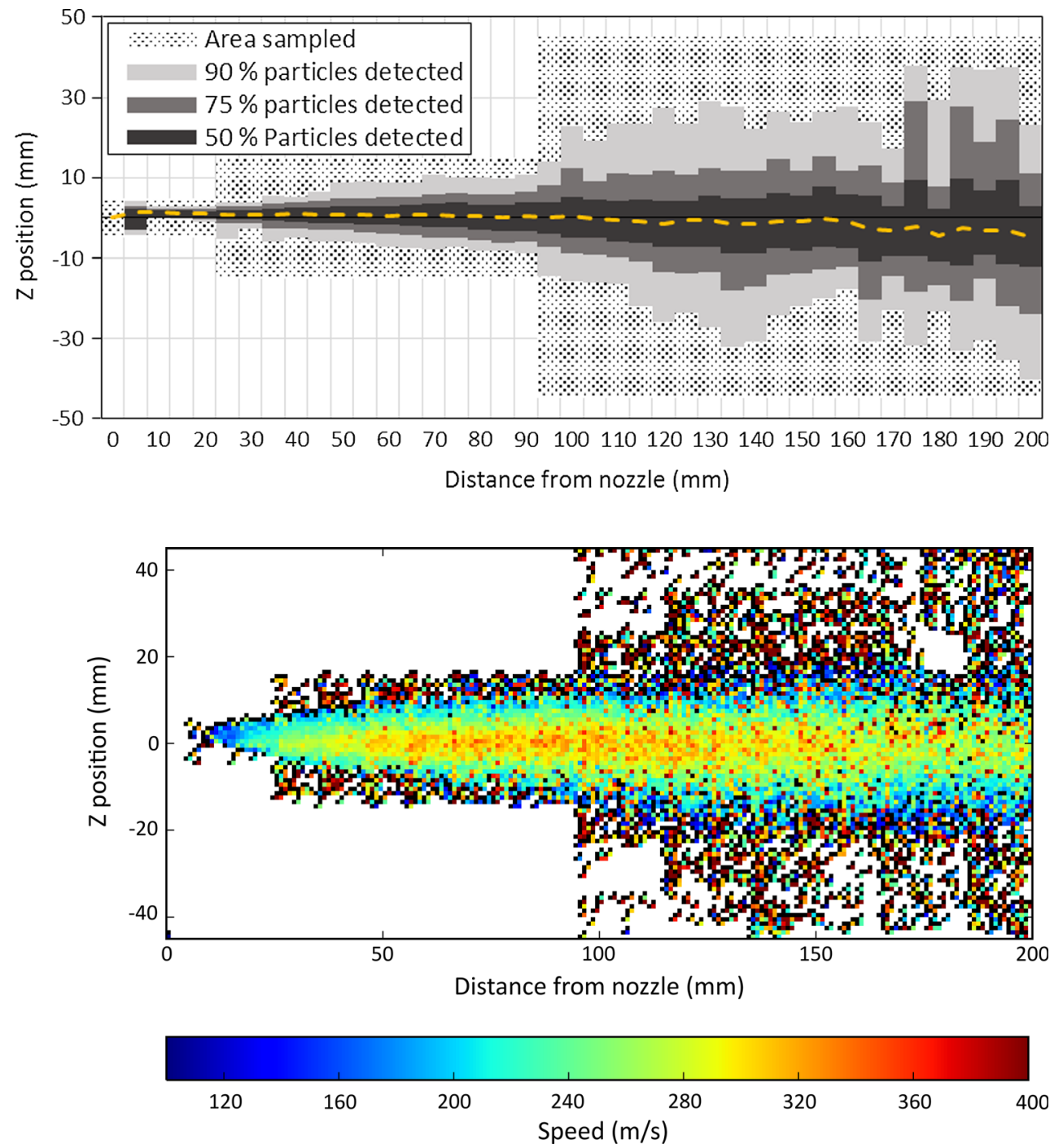

Fig. 11 The effect of distance from the nozzle exit on the mean particle velocity in the central $10 \mathrm{~mm}$ of the spray plume from SprayWatch measurements. Also shown are lines for \pm one standard deviation $(\sigma)$ from the mean

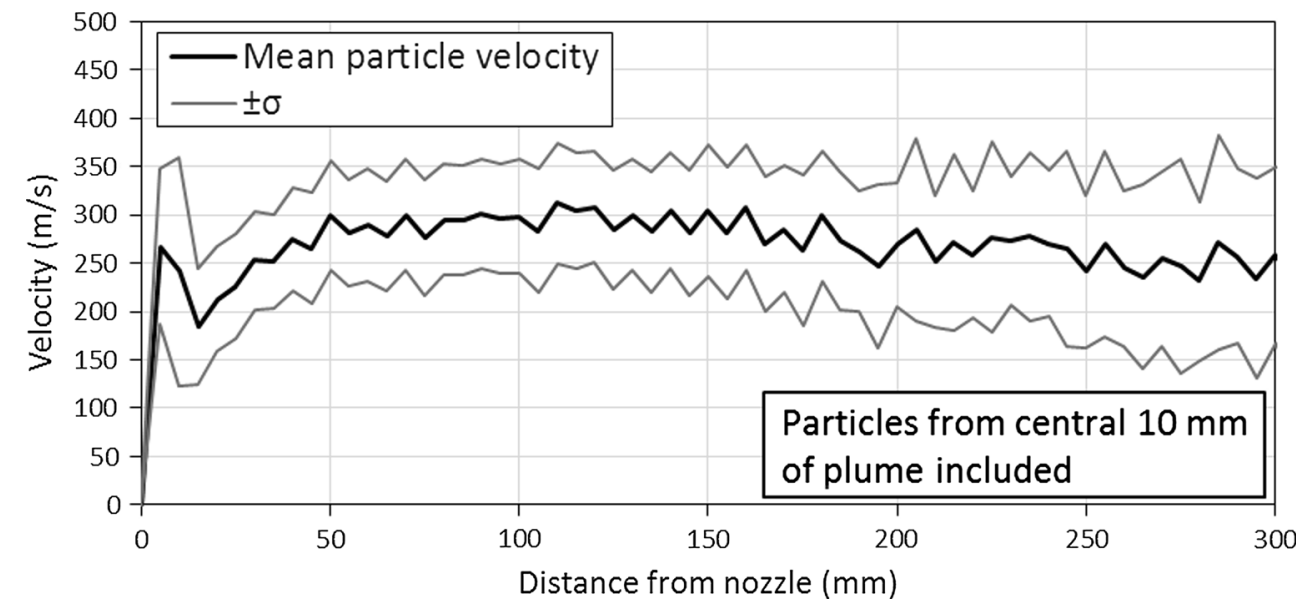

due to difficulties in the estimation of the Weber number for two reasons. First, the oxidation of the molten aluminum could affect the surface tension of the liquid metal at the tip and secondly the flow dynamics and flow conditions of the atomizing air at the nozzle exit need to be calculated more precisely using, for example, a computational fluid dynamics approach. 
Fig. 12 The effect of distance from the nozzle exit on the mean particle diameter in the central $10 \mathrm{~mm}$ of the spray plume from SprayWatch measurements. Also shown are lines for \pm one standard deviation $(\sigma)$ from the mean

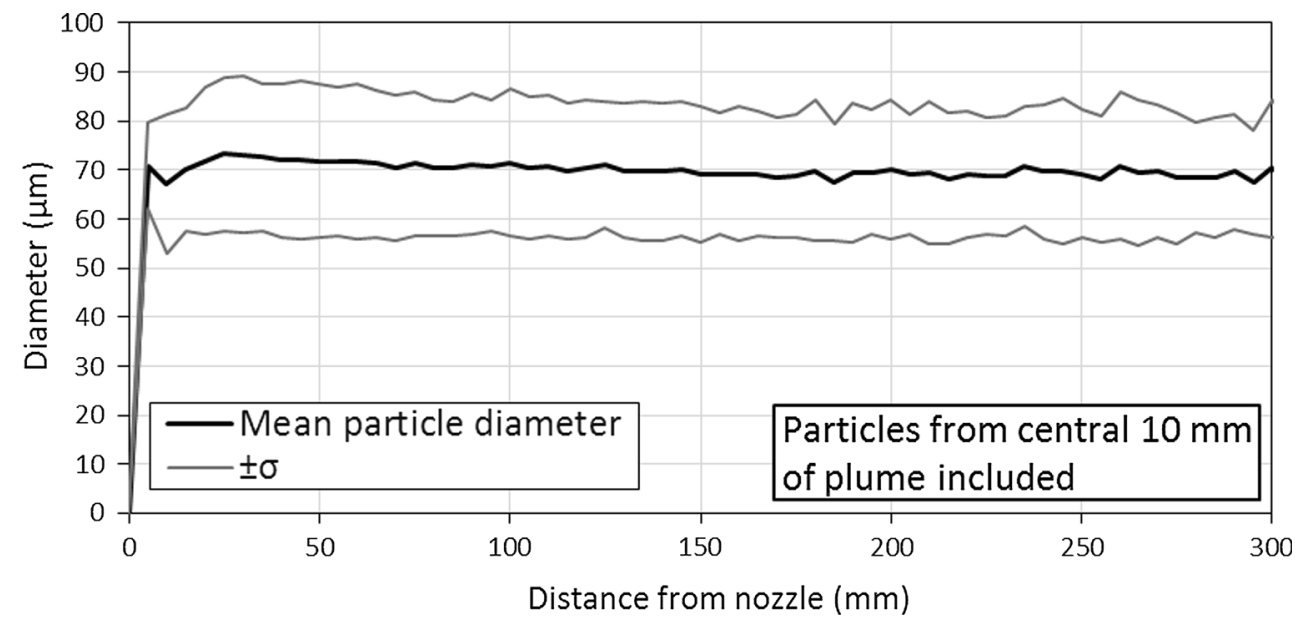

Fig. 13 Graph showing the spatial distribution of numbers of particles measured along the $\mathrm{z}$ direction at a distance of $150 \mathrm{~mm}$ from the nozzle exit. Data obtained from wipe test coupons and SprayWatch (particle diagnostic) measurements

\section{Particle Properties}

Repeated measurements of the particle parameters within the spray plume in experiments that were conducted over a period of months indicate that the plume is stable in terms of particle velocity and particle size. The average particle velocities measured are in the region of $250-300 \mathrm{~m} / \mathrm{s}$, and particle size ranges remained stable although there are limitations of the particle size measurements which will be discussed subsequently.

The measurement of particle velocities involves triple exposing images such that each particle is imaged three times per exposure, and a representative image is shown in Fig. 14. The distance between each rendering of the particle shown within the black box is $\sim 170 \mu \mathrm{m}$. The time interval between laser pulses was $0.5 \mu$ s, and so the

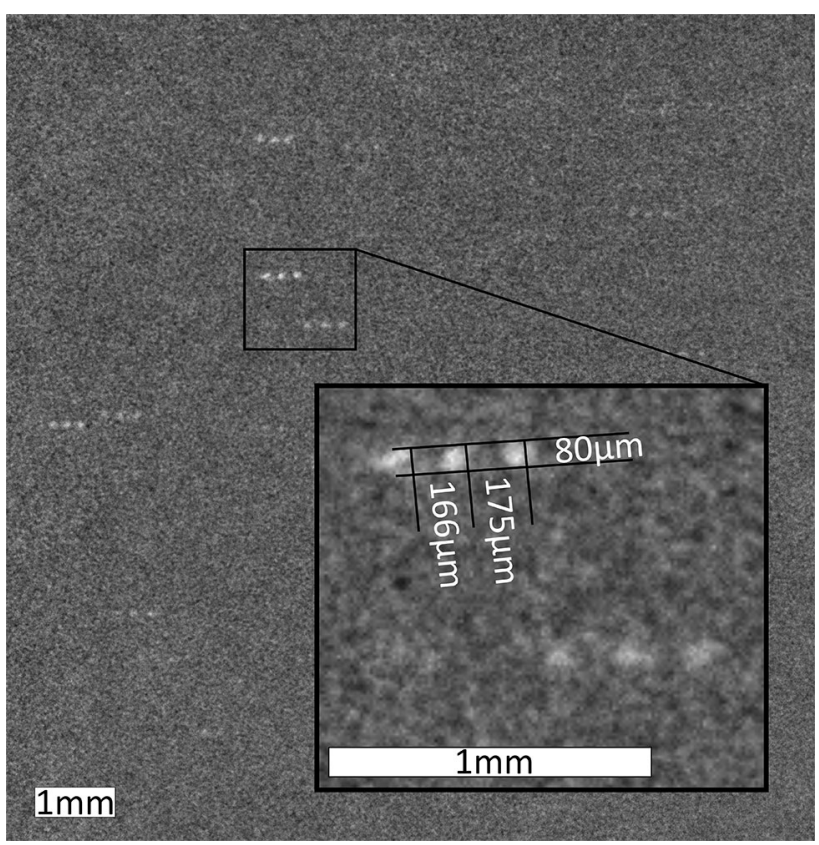

Fig. 14 Representative image taken from the SprayWatch system with measurements shown for a single particle triplet in the enlarged area of the box (inset)

distance equates to a velocity of $320 \mathrm{~m} / \mathrm{s}$. It is of note that the resolution of the diagnostic system used was $\sim 1000 \times 1000$ pixels. Combined with the optics, this means that each pixel represents $10.6 \mu \mathrm{m}$ or $20 \mathrm{~m} / \mathrm{s}$. This time interval was chosen during preliminary experiments to ensure that the particles were far enough apart that they were distinct but close enough together that they could readily be detected as triplets. The images confirm that the interval chosen was correct, and there is no evidence of particles which are blurred together in a streak because the interval is too small.

The particle velocities measured are higher than the typical reference values quoted which tend to group wire 
flame and powder flame spray together and suggest that particle velocities are below $200 \mathrm{~m} / \mathrm{s}$ (Ref 11). However, the velocities reported in the present study agree well with the single location measurements of wire flame spray particle properties performed by Dykhuizen and Neiser who measured particle velocities in the range of 50-400 m/ $\mathrm{s}$ (Ref 13). There are some (limited) studies which suggest that particle velocities in powder flame spray (PFS) are in line with values reported in reference texts (Ref 15$)$, and so the current work suggests that WFS particle velocities can be significantly greater than PFS.

One other feature found in the data is that there is not a significant correlation between particle size and velocity as demonstrated by the binned scatter plot shown in Fig. 15. Planche et al. (Ref 15) correlated particle size and velocity for several powder-fed processes (PFS, PS and HVOF). They found a general negative correlation between particle size and velocity, i.e., as particle size increased the velocity decreased. The trend was more significant for the higher velocity processes specifically HVOF and less significant for the lower velocity processes such as PS. The data collected in this study fall between these two velocity ranges of the Plache et al. study, and their data only include particles up to $\sim 55 \mu \mathrm{m}$ in powder-fed processes.

In addition to the run to run stability of the particle velocities, the velocities were relatively insensitive to both standoff distance and relatively large $( \pm 20 \%)$ changes in atomizing gas flow rate. The distribution of particles in the plume was also seen to be relatively stable as the standoff distance changed. This suggests that the WFS process (under the conditions employed in the present study) is relatively robust with respect to these parameters.

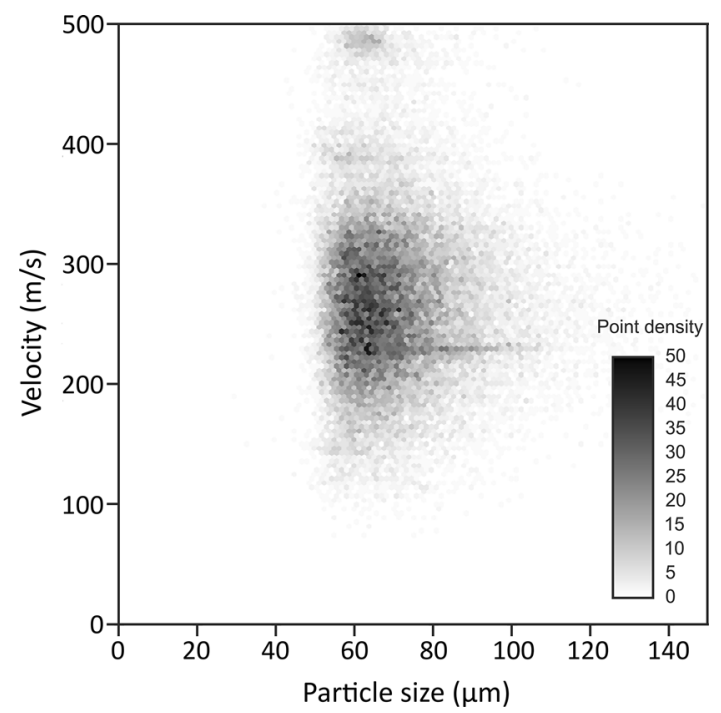

Fig. 15 Binned frequency scatter plot of particle size and particle velocity obtained from SprayWatch measurements showing there is no significant correlation
However, neither particle nor gas temperatures could be measured. As these are potentially important factors influencing final coating properties, the data collected here cannot be conclusive regarding the effect of process parameters on final coating quality.

Particles sizes were determined by measuring the diameter of the particles (normal to the direction of travel) as illustrated in Fig. 14. The measurement has to be performed perpendicular to the direction of travel to eliminate and distortion in the image due to particle movement during the image capture time. There was very little change in the particle size with position or atomizing gas; the data did not seem to fit an established distribution, e.g., normal or lognormal. The distribution of particles detected by the diagnostic system appeared to peak at $\sim 65 \mu \mathrm{m}$ and the number detected reduced as particle size reduced below that, with particles smaller than $\sim 45 \mu \mathrm{m}$ not being detected. This limitation is not surprising as in SprayWatch system used in this study each pixel in the CCD camera represented $10.6 \mu \mathrm{m}^{2}$; thus, a $60 \mu \mathrm{m}$ particle was only 6 pixels wide and represented therefore a threshold size that could be reliably detected by the sensor system. To investigate this further, splat volumes were determined by using focus variation microscopy to measure the volumes of particles collected on wipe test samples. Assuming that the particles are perfect spheres before impact, a calculated particle size distribution is displayed in Fig. 16. It is clear that the particles detected with SprayWatch were larger than any of those from measured splat volumes. This suggests that there is a low incidence of particles in wipe tests that are of a size that would be detected with the particle diagnostic system. The implication is that the

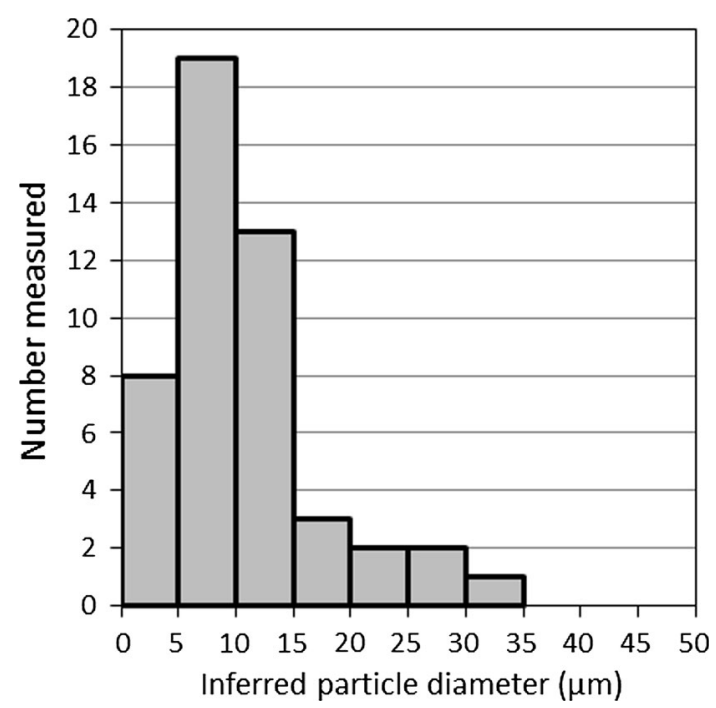

Fig. 16 Histogram showing particle diameter distribution (calculated from measured splat volume, based on 48 measured splats from multiple samples) 
particle diagnostic system is detecting only the largest particles in the plume. However, because these particles have a much greater volume (volume being a function of the cube of diameter), they are significant in terms of volume of aluminum deposited.

There is additional evidence that the particle diagnostic system is failing to detect all the spray particles. The data collected at the different measurement locations shown in Fig. 2 were analyzed to estimate the flux of material. For a plane $150 \mathrm{~mm}$ from the nozzle tip, a volume flux of $92 \mathrm{~mm}^{3} / \mathrm{s}$ was calculated. This is approximately $53 \%$ of the volume flux entering the system as calculated from the wire feed rate. However, the calculation of detected volume flux is highly dependent on assumption about the particle morphology and the 53\% value is based on the assumption that particles are spherical. Improved particle diagnostic data could be obtained using a particle diagnostic system that is capable of resolving smaller particles.

\section{Conclusions}

- An in-flight particle sensor (SprayWatch) in a backlit strobe laser configuration has been successfully used to determine the wire breakup and in-flight particle behavior of the wire flame spray (WFS) process for an aluminum feedstock.

- The WFS feedstock breaks up in a non-axisymmetric Rayleigh manor in a similar way to twin wire arc spray.

- Velocities for the detected particles were in the range of $200-350 \mathrm{~m} / \mathrm{s}$. The measured velocities were greatest in the center of plume and decreased little with distance from the spray gun exit up to a distance of $150 \mathrm{~mm}$. The velocities were also relatively constant when altering the flow of atomizing air $\pm 20 \%$ from a baseline value.

- Analysis of the measured diameter data suggests that the diagnostic system (as it was set up in these experiments) detects only those particles larger than $60 \mu \mathrm{m}$ in diameter, consistent with the system specifications.

- The spatial distribution of detected particles in the plume was measured by analyzing particle diagnostic data from multiple runs. This distribution correlated well with splat distribution data obtained from wipe tests. The plume of detected particles was shown to remain relatively narrow, even at large standoff distances.

- Overall, the process has been seen to be relatively stable (in parameters measured) to changes in standoff distance and atomizing air flow rate over the ranges investigated. The measured parameters have also been found to be repeatable in experiments conducted over a period of several months.

Acknowledgments This work was supported by the Engineering and Physical Sciences Research Council [grant number EP/L50502X/1] through an EPSRC Industrial CASE PhD studentship to G. D. Lunn. This publication was made possible by the sponsorship and support of TWI Ltd. The work was enabled through, and undertaken at, the National Structural Integrity Research Centre (NSIRC), a postgraduate engineering facility for industry-led research into structural integrity established and managed by TWI Ltd through a network of both national and international Universities.

Open Access This article is distributed under the terms of the Creative Commons Attribution 4.0 International License (http://crea tivecommons.org/licenses/by/4.0/), which permits unrestricted use, distribution, and reproduction in any medium, provided you give appropriate credit to the original author(s) and the source, provide a link to the Creative Commons license, and indicate if changes were made.

\section{References}

1. P. Fauchais and M. Vardelle, Sensors in Spray Processes, $J$. Therm. Spray Technol., 2010, 19(4), p 668-694

2. J.R. Fincke, D.C. Haggard, and W.D. Swank, Particle Temperature Measurement in the Thermal Spray Process, J. Therm. Spray Technol., 2001, 10(2), p 355-366

3. J. Larjo, High-Power Diode Lasers in Spray Process Diagnostics, in Proc. SPIE 5580, 26th International Congress on High-Speed Photography and Photonics, 25 March 2005, p 455

4. N.A. Hussary and J.V.R. Heberlein, Atomization and Particle-Jet Interactions in the Wire-Arc Spraying Process, J. Therm. Spray Technol., 2000, 10(4), p 406-610

5. N.A. Hussary and J.V.R. Heberlein, Effect of System Parameters on Metal Breakup and Particle Formation in the Wire Arc Spray Process, J. Therm. Spray Technol., 2007, 16(1), p 140-152

6. W. Tillmann and M. Abdulgader, Wire Composition: Its Effect on Metal Disintegration and Particle Formation in Twin-Wire Arc-Spraying Process, J. Therm. Spray Technol., 2012, 22(2-3), p 352-362

7. A.P. Abkenar, Wire-Arc Spraying System: Particle Production, Transport, and Deposition, Ph.D. Thesis, University of Toronto, 2007, http://www.coIIectionscanada.gc.ca/obj/thesiscanada/vol2/ 002/NR39723.PDF

8. TWI, What are the Most Common Applications of Flame Spraying? http://www.twi-global.com/technical-knowledge/faqs/ process-faqs/faq-what-are-the-most-common-applications-of-flamespraying/, 2011. Accessed 24 Jan 2017

9. R. Gonialez, H. Ashrafizadeh, A. Lopera, P. Mertiny, and A. McDonald, A Review of Thermal Spray Metallization of PolymerBased Structures, J. Therm. Spray Technol., 2016, 25(5), p 897-919

10. H. Ashrafizadeh, A. McDonald, and P. Mertiny, Deposition of Electrically Conductive Coatings on Castable Polyurethane Elastomers by the Flame Spraying Process, J. Therm. Spray Technol., 2016, 25(3), p 419-430

11. R.C. Tucker, Ed., ASM Handbook: Thermal Spray Technology, Vol 5A, ASM International, Novelty, 2013, p 9

12. C.J. Li, G.I. Yang, and Ö. Altun, Thermal Spray Coatings for Aeronautical and Aerospace Applications, Aerospace Materials Handbook, S. Zhang and D. Zhao, Ed., CRC Press, Boca Raton, FL, 2013, p 281-358 
13. R.C. Dykhuizen and R.A. Neiser, Process-Based Quality for Thermal Spray Via Feedback Control, J. Therm. Spray Technol., 2006, 15(3), p 332-339

14. R.A. Neiser, I.E. Brockman, T.J. O’Hern, M.F. Smith, R. Dykhuizen, T.J. Roemer, and R.E. Teets, Wire melting and droplet atomization in a high velocity oxy-fuel jet, Advances in Thermal Spray Science \& Technology, Sept 11-15, 1995, C.C. Berndt and S. Sampath, Ed., ASM International, Houston, TX, 1995, p 99-110

15. M.P. Planche, H. Liao, B. Normand, and C. Coddet, Relationships Between NiCrBSi Particle Characteristics and Corresponding Coating Properties Using Different Thermal Spraying Processes, Surf. Coat. Technol., 2005, 200(7), p 2465-2473
16. J. Schindelin, I. Arganda-Carreras, E. Frise, V. Kaynig, M. Longair, T. Pietzsch, S. Preibisch, C. Rueden, S. Saalfeld, B. Schmid, J.Y. Tinevez, D.J. White, V. Hartenstein, K. Eliceiri, P. Tomancak, and A. Cardona, Fiji: An Open-Source Platform for Biological-Image Analysis, Nat. Methods, 2012, 9(7), p 676-682

17. K.K. Kuo, Regimes of Jet Breakup and Breakup Mechanisms (Physical Aspects), in Recent Advances in Spray Combustion: Spray Atomization and Drop Burning Phenomena, Progress in Astronautics and Aeronautics, 1996, p 109-135

18. I.F. Bainbridge and J.A. Taylor, The Surface Tension of Pure Aluminum and Aluminum Alloys, Metall. Mater. Trans. A, 2013, 44, p 3901 